\title{
Management and Analysis of Maritime Geospatial Data During COVID-19: Case Studies, Opportunities and Challenges
}

\author{
Rafael Ponce Urbina, Orhun Aydin and Steve Snow
}

This chapter presents a holistic view of the uses of GIS to monitor, analyze and disseminate knowledge pertaining to maritime geospatial data during the COVID-19 pandemic are showcased. The challenges pertaining to authoritative data production during a pandemic are identified. Challenges faced by national hydrographic offices and International Maritime Organization (IMO) members to provide the most up to date information for the Safety of Life at Sea (SOLAS) during the pandemic is discussed. The value brought by analyzing and mapping such data during the pandemic is demonstrated with case studies on tracking the impacts of pandemic on maritime supply chains, continuity of operations for business and ports, and maintaining status of ship fleets. This chapter is concluded with public-facing analytical products that serve and analyze maritime data.

\subsection{Introduction}

COVID-19 pandemic has been disrupting human movement, travel and trade patterns on air, land and sea. Impacts of the current pandemic on maritime traffic offers challenges and opportunities to quantify the level of supply chain disruption, delineate high-risk sea routes and provide a proxy for the intercontinental spread of COVID-19.

Disruptions to maritime industry have significant consequences for the local and global economy that rely on transport and trade of goods [1]. Understanding long and short term impacts of COVID-19 on the maritime supply line disruptions is required to increase the resilience of maritime transportation systems to future pandemics, and hasten the recovery period of the maritime ecosystem.

Geographic accuracy is essential in detecting and responding to any infectious disease outbreak [2], whether is a pandemic [3], a seasonal influenza [3], or a local outbreak of food-borne illness [4]. Based on experience of GIS use supporting many health-related agencies at all levels of government, critical areas in which geospatial information is critical are summarized below:

- Assessing risks

- Evaluating threats

- Tracking outbreaks

- Maintaining situational awareness 
- Documenting disparity

- Ensuring the focused allocation of resources

- Notifying communities

- Minimizing the disruption caused by necessary community health intervention

Minimizing the impacts of the COVID-19 pandemic on the maritime ecosystem can only be possible via continuous geospatial data feeds, impactful analysis and enabling artificial intelligence systems, and disseminating data and knowledge in an effective manner. We discuss the multifaceted impacts of COVID-19 maritime industry within the context of GIS.

\subsubsection{The Use of Geospatial Data and Systems}

Location information is critical to decision making associated with large outbreaks, determining the origins of the infection, spread (speed and direction) and measures to isolate it, how to respond to it and how to organize the work force to minimize disruption as much as possible [5].

Location intelligence becomes even more critical when the outbreak can no longer be contained through contact tracing and quarantine [6]. Location-based information can be used to inform multiple, specific community interventions and activities [7]. Using common types of GIS analysis, such as mapping where things are, mapping the "most" and "least", mapping disease density, finding "what's inside" or "what's nearby", and mapping change, authorities can prioritize interventions and re-organize their resources [8]. Time is another crucial dimension that is naturally represented inside GIS [9]. Temporal and spatio-temporal analysis of geo-enabled data pertaining to COVID-19 is essential understanding current trade delays and supply line disruptions [10].

The maritime community, especially the shipping industry and port authorities, need geospatial information to safeguard the integrity of the logistic chain to maintain the essential goods supply during the pandemic. [11].

\subsubsection{Impacts on the Maritime Community}

The maritime community is wide and includes many different sectors, all connected in one way or another, and all suffering the impacts of the COVID-19 pandemic [12]. In an attempt to simplify this complex ecosystem, we have divided it into those sectors that affect the so called blue economy, with two large branches: shipping and ports. In this classification, we exclude fisheries and tourism (leisure yachting) despite their importance to local and global economy. Local and partial data pertinent to fisheries and tourism makes it cumbersome to evaluate the global challenges pertinent to and the use of maritime geospatial data during the COVID-19 pandemic.

The shipping industry has been significantly impacted by the pandemic. Broadly, we can divide this impact in three main categories:

- Cargo or goods (containers and bulk)

- Oil and gas (tankers)

- Passengers (cruise liners)

The transport of goods and hydrocarbons appear to have been operating consistently, which is true in some respects. That and the global economic downturn are presenting unprecedented challenges that can cause disruptions in the supply chain. Some estimates by the International Monetary Fund estimate global GDP growth will fall 3\% in 2020 [13, 14], and the World Trade Organization (WTO) expects a fall in trade between $13 \%$ and $32 \%$ [15]. Depending on the duration of the outbreak and how governments deal with it, there could be a partial recovery in 2021 [14].

According to the WTO the most affected sectors in Q2 2020 have been automobiles and containers and have seen a weak demand for goods in general as well as some constraints in the supply chain [14]. The largest container company in the world, Moller-Maersk has stated that container volumes could be around 25\% lower in Q2 2020 [14].

Because of countries reducing the risk of infection of COVID-19, ship traffic has been reduced by approximately $25 \%$ in the first half of 2020 . The pandemic has resulted in less demand for 
imports and exports of cargo between countries. Many goods that cannot store for 14 days cannot be shipped due to 14 day waiting periods in quarantine. Because of the reduced demand for cargo many companies have become bankrupt due to the pandemic.

In the oil and gas sector, besides the common impacts to navigation, ship's maintenance and crew rotation, specific situations such as the floating oil storage can be significantly affected. Because of the drop in oil prices due to high production with low demand, the need for floating storage has skyrocketed. According to S\&P Global Platts, in May of 2020 there were more than 200 million barrels of oil and derived products on floating storage in tankers, which is around $5 \%$ of the global carrying capacity. These tankers will need maintenance and to fulfill contractual requirements. Many tankers are at anchor or idling near major ports around the world with the risk of getting exposed to extreme weather conditions, potential piracy activities and in some cases, to political conflict. The longer these tankers stay at sea fully loaded, the bigger the risk of cargo degradation or loss because of the extended time or worse, the risk of accidents and environmental pollution.

As per the cruise industry, it generates an estimated $\$ 150$ billions in global economic activity, supporting more than one million jobs worldwide [16]. This sector is perhaps the one that is most impacted by the pandemic, with almost no activities due to several COVID-19 outbreaks on board, travel restrictions, port closures and prohibition to sail from the US Center for Disease Control (CDC) since March of 2020 [17]. With around $95 \%$ of the global cruise fleet in lay-up, there are concerns on risks for both, ship owners and insurance companies due to the Atlantic hurricane season, considering that almost half of those ships are in and around the Americas. Similarly, for the typhoon season in the Pacific. Other important impacts are the costs of having these ships laid-up for an extended period of time, which is estimated between $\$ 1$ million and $\$ 3$ million per month and the costs of bringing them back to service.

Those above are perhaps the most evident impacts to the shipping industry, but there are other less visible and equally important aspects that are being impacted, such as disruptions on machinery maintenance and repairs, ship owners risk delays on scheduled maintenance and services, disruption in the supply of spare parts and other essentials such as lube-oil and hydraulic oils and travel restrictions for specialist engineers to access the ship to provide maintenance or repairs. Engines can also be damaged by delays in the analysis of sulphur emissions, because of the cap on sulphur emissions under International Maritime Organization (IMO) 2020, vessels have been using blended low-sulphur fuels, which in order to avoid engine damage, require analysis prior to be used by the ship's engines. This requires the dispatch of fuel samples to shore-based laboratories and with COVID-19 restrictions, it may not be possible to do in time. There are manuals that detail how to proceed with on board testing kits and there is the possibility to use distillate fuels as an alternative, but the normal procedures are disrupted. There are several other areas of the shipping business impacted by the COVID-19, the examples above, are meant to give a sense of the deep effects this pandemic has in the industry. The maritime ports sector has seen a reduction in containers volumes, quarantine of vessels by ports for 14 days, port closures, and port operations in general.

Reduced operations and personnel have an impact on possible cargo damage, which if stored in high risk areas without the appropriate security controls can run the risk of losses from fire or extreme weather conditions and delay in the supply chain can also result in cargo damage, mainly to perishable or temperature-sensitive goods. With vessels being quarantined and ports being quarantined cargo movement is delayed. This will also have an impact on the insurance industry, with a potential increase of claims.

\subsubsection{Significance of Machine Learning for Maritime During COVID-19}

Problems pertaining to every subsystem in the maritime ecosystem rely on accurate data and reproducible analysis that result in data products. In addition, maritime data has the potential to serve as a proxy for COVID-19's impact on global trade [18]. The availability and density of maritime data require scalable deployment of artifical intelligence to extract patterns [19], find anomalies [20] and forecast disruptions [21]. Live maritime data has the potential to be an early warning sign for supply line disruptions due to COVID-19 [22]. 
Shipping and maritime data, depending on the source, can be represented one of three ways:

1. Track/movement analysis

2. Spatio-temporal analysis

3. Time-series analysis

Depending on the aims of the maritime community all approaches have the potential to answer important questions pertinent to supply chain and trade activity during the COVID-19 pandemic. Movement prediction is another useful data product obtained from track-level analysis of vessel movement [23]. Anomalies and movement prediction are important components for maritime community to ensure safe navigation, an ever important topic during a pandemic and associated supply line disruption [22]. Spatial analysis of maritime data has provided proxies for secondary sources of information on ship movement that is not available publicly in real time. In particular, satellite imagery from ship emissions and ship wakes are used to reconstruct ship tracts which in turn can be used for further analysis [24]. Track and movement analysis for maritime data is performed at the agent level and movement anomaly detection methods are frequently used to identify unexpected movement of vessels [25].

Spatio-temporal analysis of ship traffic using Getis-Ord statistic [26] has shown to effectively detect bottlenecks of ship traffic at natural and artificial confinements, such as ports and straits [27]. In addition, space-time analysis of ship tracks from AIS feeds has been found useful for delineating areas where shipping volume is observed to drop unexpectedly. Despite differences in their formulation and uses, operationalizing artificial intelligence during the COVID-19 pandemic requires uninterrupted data streams, near real-time data curation and resilient analysis networks to ensure information flow on issues of vital importance to communities on supply-line disruption.

\subsubsection{The Maritime Ecosystem's Needs for Data \& Challenges}

As discussed above, maritime transport is more important than ever, ships must keep moving, ports need to stay open and cross-border trade flowing. Besides the challenges in maintaining the supply chain, there is a human factor that is no less important. The shipping industry normally replaces crews every certain time, this operation is becoming very difficult. The International Maritime Organization (IMO) has promoted the key role seafarers play during the pandemic and the need to recognize them as key or essential workers, by identifying the dangers they face while doing their jobs.

This pandemic has created an unprecedented crisis for ship crews, with the difficulties to travel and restrictions imposed by governments and port authorities, the normal crew change that periodically has to happen has been interrupted and in many cases seafarers are stuck at sea way passed the due time, creating health risks and safety issues.

Normally more than 100,000 seafarers must be changed monthly in order to comply with international regulations for crew welfare and safe working hours. In the current situation, it is estimated that around 400,000 seafarers are being impacted by the COVID-19 restrictions.

The International Transport Workers' Federation (ITF), that represents about 1.4 million seafarers, has decided not to celebrate the 2020 Day of the Seafarer, due to the humanitarian crisis that the travel restrictions have created at sea. The global supply chain could be at risk.

The IMO together with the United Nations Conference on Trade and Development (UNCTAD) are encouraging governments and maritime industry stakeholders to take a pragmatic approach, such as granting exceptions and waivers where they are appropriate. Also, the use of technology and electronic means for communications between ships and shore, encouraging governments and maritime industry stakeholders to take a pragmatic approach, such as granting exceptions and waivers where they are appropriate. Here is where the use of Geospatial Information in the application of IMO e-Navigation principles should be used in order to provide maritime services that facilitate and expedite administrative, commercial and operational activities. E-Navigation is a way to systematically ensure "berth-to-berth navigation", improving efficiency when a ship is approaching the port. 
In this sense, the "Single Window" concept, at least for some of the most important activities should be implemented. The e-Navigation concept for a "single window" is where a ship (or a shipping company) can access a series of services from registered service providers before arriving the Port.

In this topic there are important geospatial aspects to consider from another organization, the International Association of Marine Aids to Navigation and Lighthouse Authorities (IALA), which standards such as the IHO S-200 series and organizations like the PortCDM Council (Collaborative Decision Making) will contribute in improving efficiency coming in to and going out of a port.

The International Hydrographic Organization (IHO) is the entity in charge of developing standards and specifications to be applied to products and services used in the maritime world. They have developed the S-100 standard, officially called the Universal Hydrographic Data Model, from which many new product specifications are being developed. Most if not all national hydrographic offices around the world follow IHO standards in one way or another. As per the COVID-19 pandemic, IHO has not emitted any specific guidelines or recommendations to its members, but they have suspended all in person meetings and activities, including the General Assembly meeting that did not take place in 2020 as scheduled.

While normally the bulk of the organization's work happens by correspondence, there is important work that occurs during technical working group physical meetings, that has the advantage of isolating themselves from the day to day work for one week to make significant advancements in developing standards and make key decisions with all the relevant stakeholders present in the same room. These on-site meetings have been replaced with webcasts in an effort to continue with their working plans and minimize the effects of the pandemic on their work.

National hydrographic offices are the authoritative government agencies, equivalent to national mapping agencies on land, in charge of producing navigational charts and other complementary information products for safety of navigation. Some of these agencies in general have experienced challenges for keeping up with their regular production and updating services, and they have been adapting to the pandemic circumstances in different ways. As we will see in the NOAA use case below, some agencies have implemented enterprise systems that allow them to work remotely and continue with their regular activities as close as possible to the normal times.

Hydrographic surveying activities in general cannot be performed in the office, there are many phases of this type of surveys that need to be performed on the field, and sometimes physical distancing between hydrographers is almost not possible, if we consider a small hydrographic survey boat with two or three hydrographers on board collecting data together for long periods of time or a larger hydrographic survey ship at sea with crew confined in small compartments for several weeks in a row.

Similar situation and risks are being experienced by land surveyors, and many governments around the world have implemented guidelines to increase safety of their workers while in the field. Although these measures and guidelines are often generic and not specific to surveyors, much less to hydrographic surveyors.

Oftentimes hydrographic surveys are not on the top of the list of priorities during a pandemic, but the need to keep the navigational routes mapped and up to date is as important as keeping the shipping fleets moving. There is no hard evidence that the hydrographic surveying activities around the world have diminished to the point to consider them in crisis, but there are signs of some reduction of activities, this is true for both government and private organizations. Because a pandemic is not the same as a meteorological phenomenon such as a hurricane or typhoon, the characteristics of coastal waters haven't been affected, then there is not an immediate or emergency need and surveying activities can be planned carefully following all the appropriate measures.

On the other hand, nautical chart and related information production are activities that can be done remotely or from home. Many national hydrographic offices around the world have implemented telework measures in order to keep up with the necessary production updates and distribution of digital publications. Thus, nautical data products can be effectively served with the exception of some activities that require onsite labor such as the distribution of printed nautical charts and other paper nautical publications. 


\subsubsection{Challenges Faced by Information Product Providers}

The standards related to the S-100 Universal Hydrographic Data Model [28], are geospatial data standards that can support a wide variety of hydrographic-related digital data sources. S-100 is fully aligned with mainstream international geospatial standards, specifically the ISO 19000 series of geographic standards. This alignment enables easier integration of hydrographic data and applications into geospatial solutions. S-100 is more flexible than the old S-57 and enables the use of imagery and gridded data types, enhanced metadata and many encoding formats. It also provides a flexible and dynamic maintenance regime for features, their attributes and portrayal through a dedicated Registry online. One can think of S-100 as a framework of components that provides instructions for building standardized Product Specifications for hydrographic data, enabling true interoperability between different data standards and systems.

The IMO e-Navigation [29] is defined as the harmonized collection of marine information, its integration and exchange for "presentation and analysis both on board, and ashore by electronic means to enhance berth to berth navigation and related services for safety and security at sea and protection of the marine environment" [30].

The term "Single Window" can be understood as the point of contact for communication in relation to ship-to-shore and shore-to-ship. In this sense, it's mentioned in the IMO resolution A.950(23) "Maritime Assistance Service" (MAS) adopted on 05 December 2003. "Single Window" can also mean a service or institution on land that collects all information related to safety of navigation before sending them to ships, as defined in IMO documents on e-Navigation. The information products and services to be provided by the IMO e-Navigation single window concept should be based on standards that would allow them to be used anywhere in the world. In this sense, the IHO S-100 series are perhaps the most important one.

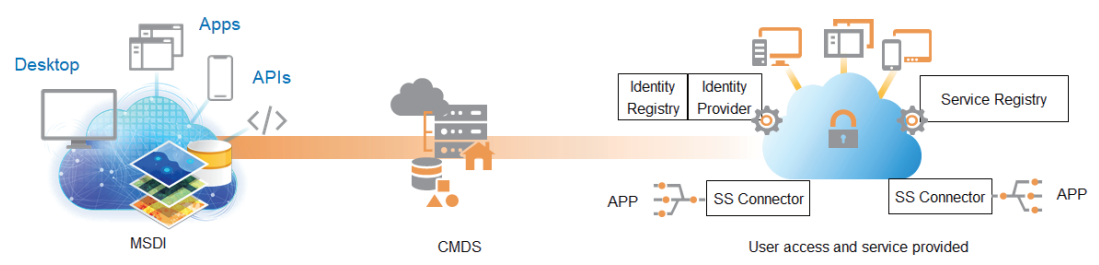

\section{FIGURE 9.1}

Geospatial Information to the e-Nav "Single Window" concept (Source: https://www.esri.com/)

By adopting S-100 standards, there are new products and services that can be provided following the e-Navigation concept from which the Maritime Service Portfolios (MSPs) can be developed and shared through a Common Maritime Data Structure (CMDS), which could be considered a derivation or extension of a Marine Spatial Data Infrastructure (MSDI). The Hydrospatial Agency not necessarily has to create the CMDS, but the MSDI should provide the "connectors" to feed a CMDS with their products and services.

The role is not anymore constrained to producing nautical charts (and in some cases Sailing Directions, Notice to Mariners, Tide Tables and related information), through this type of infrastructure, authorities and service providers can go beyond that. Bathymetric Surfaces, Near Real Time Tides and Currents, Under the Keel Clearance Management, Marine Protected Areas, and more necessary information can be provided through MSPs. Port Authorities and Administrations will benefit from this, Port Pilots, Dredging Operations, Port Security, Port Services, Port Logistics, will certainly be improved through these MSPs.

The right side of the graphic above shows the e-Nav concept for a "single window" where a ship (or a shipping company) can access these services from registered service providers before arriving the Port. The PortCDM Council (Collaborative Decision Making) has taken the role of developing the S-200 series of standards for IALA, being the first one developed the S-211 standard for Port Call Messages, standardizing sharing of data on Intentions and Outcomes of Movements, Services and Administrative events.

All the above mentioned systems are an integral part of what is commonly known as "Port 
Community Systems" (PCS), which are open and neutral platforms that can connect multiple systems together with the purpose to provide intelligent and secure exchange of information between different organizations that participate in a seaport community, such as agents and shipping lines, customs and excise, logistics providers, terminal and warehouse operators. A PCS can integrate into a national single window or act as a national single window.

\subsubsection{Working Remotely and Disconnected}

The COVID-19 outbreak has made maritime organizations and geospatial authorities rethink how the modern workplace can operate during major disruptions.

Maritime software, such as ArcGIS will support the management and production of maritime data that is compliant with the International Hydrographic Organization's (IHO) S-4, S-57 and S-100 series of standards.

With the COVID-19 crisis engulfing and disrupting businesses, it has become necessary for our national mapping agencies and industry leaders and experts, to reevaluate ways for maintaining successful business continuity.

As the workforce adapted the organization's senior leadership team implemented powerful operational tools that ensured production was maintained and tracked across environments. Two actions that were taken were

1. Enablement of virtual and disconnected environments

2. Automated apps and dashboards that optimized the organizations' communication responsiveness.

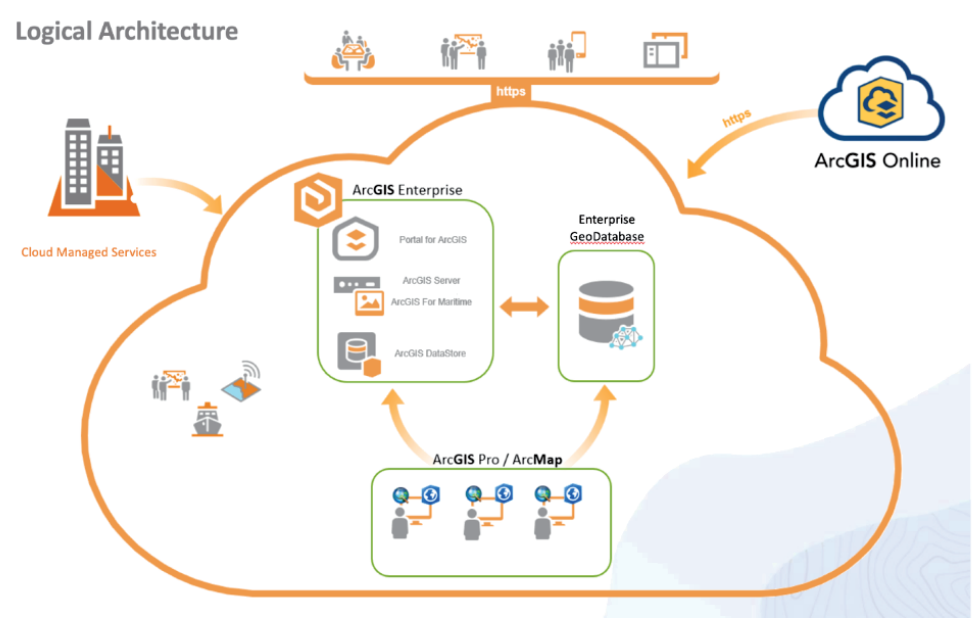

\section{FIGURE 9.2}

Leveraging Virtual, Disconnected, and Cloud Environments with ArcGIS (Source: https://www. esri.com/)

First action requires leveraging virtual environments and disconnected editing. This offered GIS users the advantage of working remotely with large amounts of geospatial information including maps, statistics, imagery, and other forms of remotely sensed data which exists across multiple distributed networks or in the cloud. This was done using via virtualization and disconnected work loads. Virtualization allows remotely connecting to a server GIS (such as ArcGIS Enterpise) with desktop virtualization. This provides the ability to collaborate directly with colleagues in a multi-user environment. Disconnectedness enables completing tasks, projects, and production. Reconnect later to synchronize work with the larger workforce.

The second action requires leveraging automated templates for apps and dashboards that 
optimize communication and workflows. Organization are now driven to adapt to unexpected yet urgent catastrophes like the COVID-19 pandemic, with accurate ready-to-use apps and dashboards, for building and reporting critical information to stakeholders, constituents and at-risk groups. Customized (COTS) out of the box Operations Dashboards, tools, GIS software, predesigned templates, libraries of reusable widgets and applications like the WebApp Builder give instant ability for performing time-sensitive decision making and building optimized workflow communication strategies.

\subsection{Case Studies}

The importance of maritime data acquisition, analysis via machine learning and AI and data product dissemination is elaborated with three case studies, one from NOAA and two from ESRI, respectively.

\subsubsection{National Oceanic and Atmospheric Administration - Office of Coast Survey}

The pandemic has forced the NOAA Office of Coast Survey (US National Hydrographic Office) to re-organize the way they conduct business. The safety of navigation in US waters is one of Coast Survey's main responsibilities and updating navigational charts is one of their most essential functions. Prior to the COVID-19, Coast Survey's Marine Chart Division (MCS) had developed an on-site sever-based system that allowed their staff and contractors to work remotely when needed, so when the pandemic struck and the need to establish physical distance for everyone, they could quickly shift one hundred percent of its workforce (more than 100 cartographers) to a work-from-home status. During this period the Division has continued to apply updates to nautical charts and has made progress on its effort to rescheme the suite of nautical charts in the United States according to their cartographic plan.

The MCD system relies on Citrix, allowing users to connect to a virtual server or desktop application remotely, so there is no need for a program to be installed on the local or physical system. MCD cartographers connect to their IT services from home via internet connection. Security is ensured by using VPN and a single sign-on (SSO) and advanced security controls. Using an application called XenApp, that facilitates the installation of applications on a server that can be accessed without having to install anything on the client machine, except for the Citrix client software, cartographers access the ArcGIS-based enterprise chart production system, called "Nautical Chart System II" (NCPSII).

In this way, all the processing happens on the server, through mouse clicks and keystrokes from the client that feels like if the production software is running locally, and the client screen refreshes from the responses to the server through a remote display protocol called "Independent Computing Architecture" (ICA).

The configuration of Citrix, together with the ArcGIS-based NCSII, was a key step in preparing the workforce to work remotely. However, a very important factor might be the general willingness of the users and management to work remotely before the pandemic started. NOAA OCS had already set up infrastructure - hardware, software and the user's understanding of how to work from home. Every staff member was provided with a laptop with the appropriate software installed to enable them to work remotely even if they were not currently teleworking.

They also benefit from robust virtual meeting capabilities that allow system administrators to work directly with the users to run upgrades and troubleshoot problems. This enabled OCS to keep the virtual convenience of working shoulder to shoulder.

With this arrangement, the Marine Chart Division has kept up with their usual production activities. They have been updating charting products and have been applying all critical (dangers to navigation) corrections to their products. In addition, MCD has also reschemed 259 ENCs during 


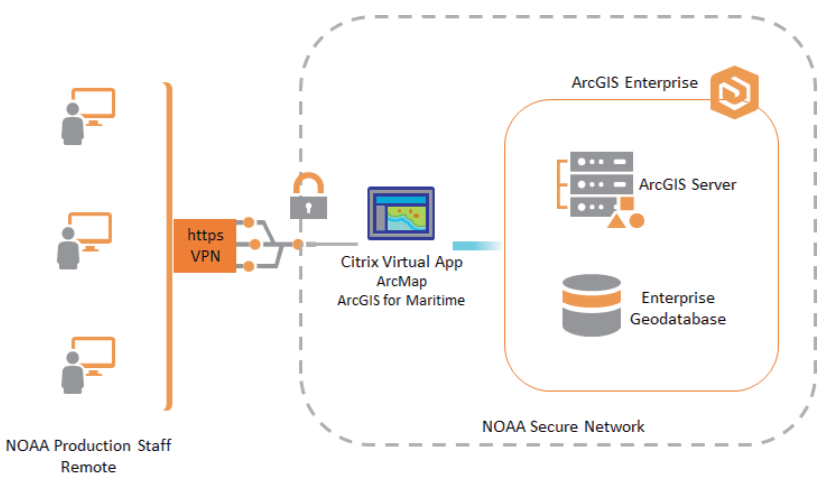

\section{FIGURE 9.3}

NOAA's Nautical Chart System for remote work diagram (Source: https://www.esri.com/)

the work from home period, continuing with their modernization plans that include retiring paper nautical charts.

Working remotely has been a positive experience, thanks to the NCPSII platform capabilities and flexibility, the overall productivity has not been affected, these results are causing OCS to consider the possibility to increasing their flexibility with regard to telework, although there is no official guidance for the post-pandemic activities.

\subsubsection{Space-Time Analytics for Quantying Impacts of COVID-19 on Shipping Trade}

Restrictions due to COVID-19 measures impact maritime traffic and all sectors of the economy that rely on maritime transport of goods. Live space-time data plays an essential role to for modeling and pattern mining studies to quantify current status of traffic restrictions, expected delays of transported goods and changes to port activity.

We use time series clusters and space-time patterns in the Oxford COVID-19 Government Response Tracker's (OxCGRT) stringency index which quantifies the extent to which governments take actions to restrict day to day activities [31]. The index is the average of 17 selected mitigation and suppression measures employed by different countries [31].

Daily stringency index mapped at the county-level is aggregated into a space-time structure, the space-time cube. Space-time patterns of the stringency index are mined by classfying the local changes to the Getis-Ord Statistics, namely the $G_{i}^{*}$ statistics (Getis and Ord, 1992). The $G_{i}^{*}$ tatistic is a z-score where extreme values imply significantly high (hot-spot) or significantly low (cold-spot) in a spatial neighborhood compared to the global average of stringency index. $G_{i}^{*}$ values close to zero implies stringency index in the area is similar to the global average at a given time.

Stringency index space-time patterns are depicted in Figure 9.4. Space-time patterns indicate Russia and parts of South America as Oscillating Hot-Spot. This pattern means these countries and their neighbors oscillate around global average for stringency for extended periods of time and go above the global average for short periods of time. Locations that are classified as sporadic hot spots go above the global average for stringency at certain times and fall back to the average. Majority of Europe exhibits oscillating cold spot which indicates stringency is lower than global average at certain times.

Space-time patterns of stringency informs the expected maritime opening and closures of an entire region using data from neighboring countries. This space-time metric gives a clear idea of how regions of the world may open up over time and which regions are still under high stringency measures.

We also performed a time-series analysis of stringency per country to assess when maritime traffic may return back to normal as stringency measures are lifted at the country level. 


$\begin{array}{llll}\square \text { New Hot Spot } & \text { Sporadic Hot Spot } & \text { Intensifying Cold Spot } & \text { Historical Cold Spot } \\ \text { Consecutive Hot Spot } & \text { Oscillating Hot Spot } & \text { Persistent Cold Spot } & \text { No Pattern Detected } \\ \text { m Intensifying Hot Spot } & \text { Historical Hot Spot } & \text { Diminishing Cold Spot } & \text { <all other values> } \\ \text { Persistent Hot Spot } \square \text { New Cold Spot } & \text { Sporadic Cold Spot } & \\ \text { Diminishing Hot Spot } & \text { Consecutive Cold Spot } & \text { Oscillating Cold Spot } & \end{array}$

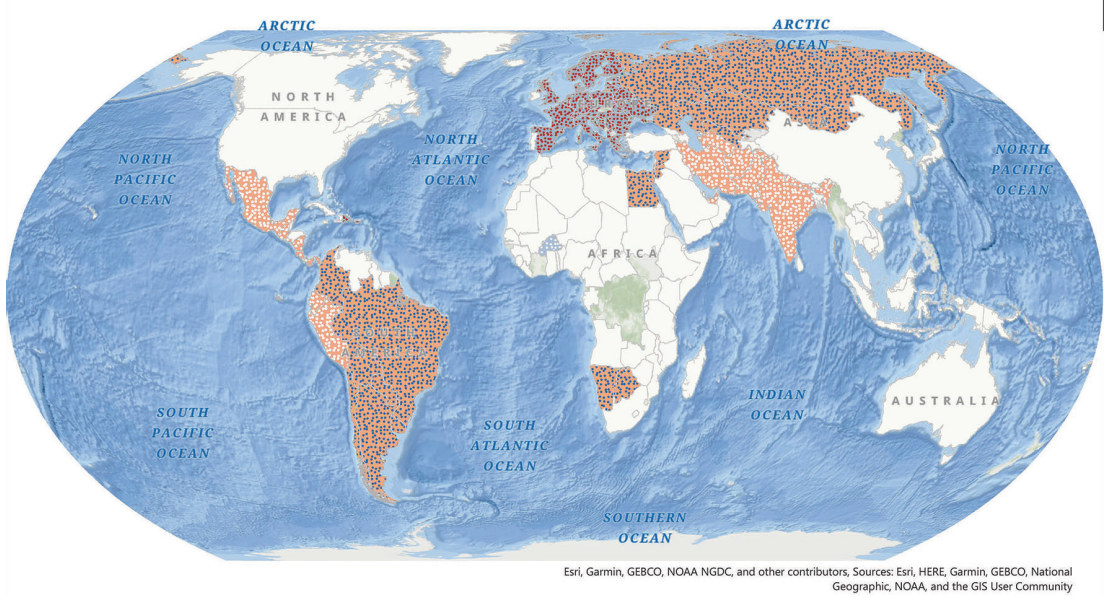

FIGURE 9.4

Emerging Hot Spot Classes of Oxford's COVID-19 Government Response Tracker (OxCGRT) Stringency Index (Display variable)

Three clusters identified in Figure 9.5 indicate change of stringency of countries over time. Blue time series clusters show a high rate of increase in the stringency index, this can imply reduced ship traffic from these countries. Red cluster indicates countries that started their stringency measures later on increase at a higher rate. Green countries are the ones with stabilizing and a lower level of stringency.

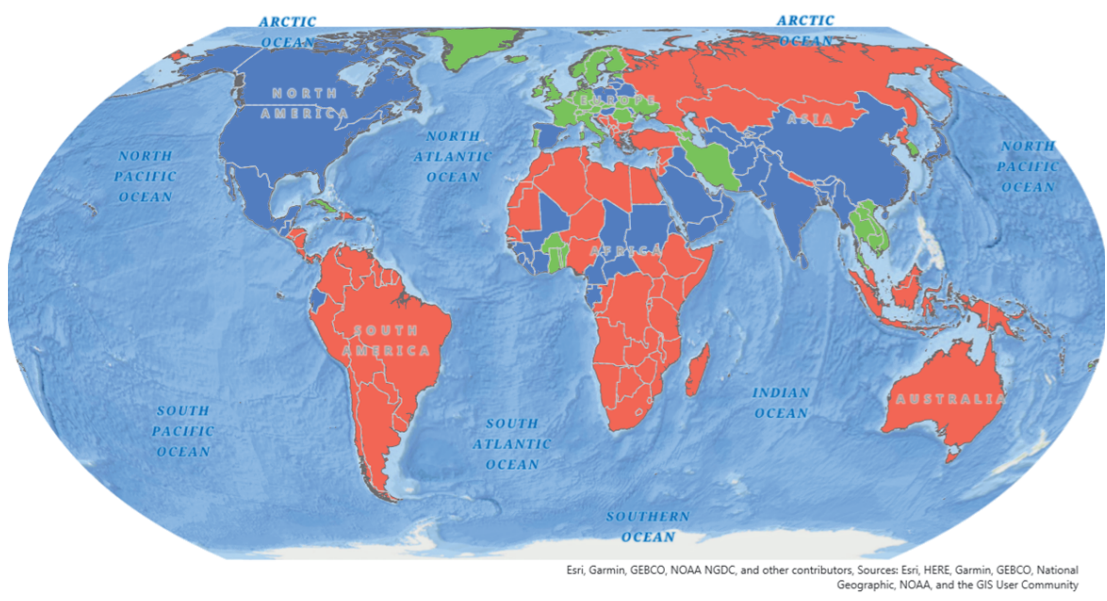

\section{FIGURE 9.5}

Time-Series Clusters of Oxford's COVID-19 Government Response Tracker (OxCGRT) Stringency Index (Display variable) 
Average Time Series per Stringency Cluster

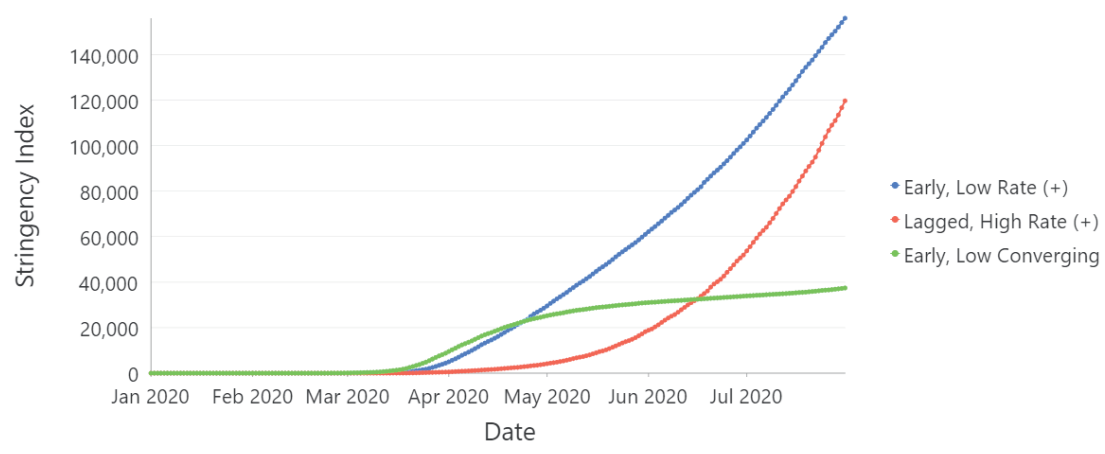

\section{FIGURE 9.6}

Time Series Clusters (same coloring scheme as Figure 9.5 of Oxford's COVID-19 Government Response Tracker (OxCGRT) Stringency Index (Display variable)

Figure 9.6 demonstrates the challenges awaiting the maritime industry due to COVID-19 as some countries are getting ready to resume regular daily activities and others deeper into the pandemic with strict measures. Three distinct time series are labelled with respect to when stringency measures were imposed and the rate of increase in their stringency measures over times. Note that countries symbolized with blue in Figure 9.5 started stringency measures earlier and their measures have been increasing ever since. Red group countries started lock-downs later but they have been ramping up efforts at a high rate. Green countries have a converging profile for their stringency measures which are not extensive as the countries in blue and red groups.

The spatial heterogeneity of imposed lock-downs and reductions to business activity indicate that even after the pandemic is declared to be over, a significant lag is to be expected for supply chains to return back to normal. Countries marked with green in Figure 9.5 are expected to ramp up their trade activities as the pandemic is under control, however countries with large trade volumes such as United States and China that fall under the blue category will need more time for their maritime operations to go back to normal.

\subsubsection{Disseminating Live Traffic Data During the Pandemic: ESRI Ireland}

One threat to maritime was the occurrence of outbreaks on vessels. The effects of such outbreaks had a major impact on economic and trade activities. In 2018 the cruise ship industry was estimated to be worth over $\$ 29.4$ billion dollars and it is predicted to carry over 19 million passengers annually. An important tool used to monitor and measure global vessel movement is the Automatic Identification System (AIS). AIS uses ship transponders and satellite communications which feed into Vessel Traffic Services (VTS). From these data feed ships with known outbreaks were tracked and monitored.

In early 2020, COVID-19 hit the leisure cruise ship industry which resulted in many issues of quarantine and the need to provide medical assistance to those in dire need. In Europe, ESRI Ireland created a web-based Global Vessel Dashboard dashboard using vessel traffic from the AISHub to monitor the situation. The AIS hub collates and shares vessel data collected from approximately 750 tracking stations run by the AISHub community. ESRI Ireland enriched the raw vessel data with information on cruise ships that reported COVID-19 outbreaks using public data. 


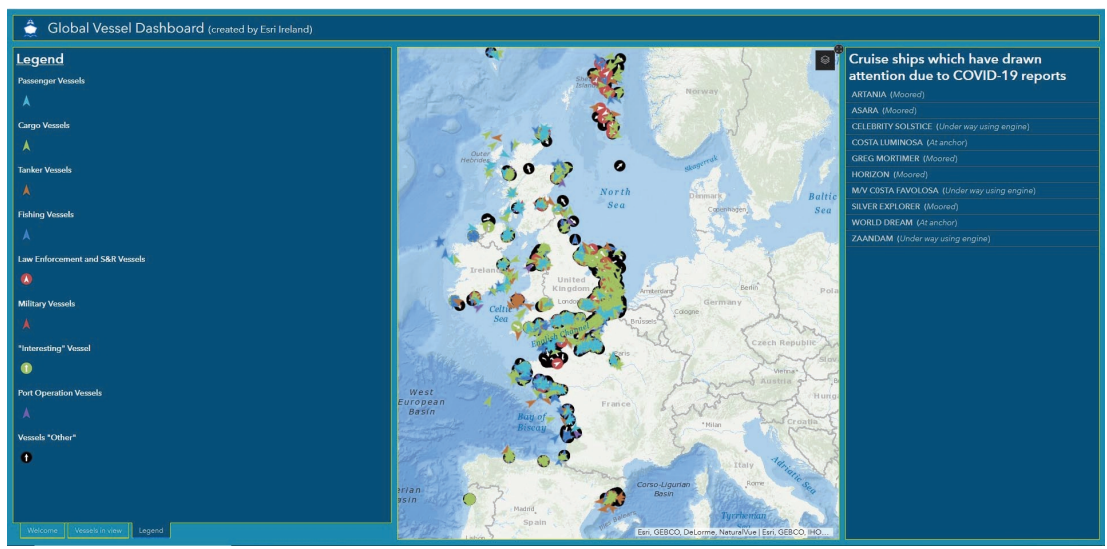

\section{FIGURE 9.7}

ESRI Ireland's Maritime Dashboard for Vessel Traffic in Europe

\subsection{Conclusions}

By leveraging geospatial technology using existing GIS capabilities, national mapping agencies and geospatial authorities can address continuity of operations, leverage virtual and disconnected environments, and optimize communications and workflows. These approaches can be used individually or collectively to ensure mission and business success during a time of crisis. NOAA's work on implementing data standards and virtualization is a representative example of opportunities in maritime for operationalizing geospatial servers that leverage maritime data conforming to international standards. It is important to note that the remote infrastructure for data collection, mapping and dissemination has resulted in positive outcomes for the scale that is required by a large organization such as NOAA. ESRI Ireland's data dissemination method through dashboards shows the value of geospatial maritime data visualization and interactive data dissemination during the COVID-19 pandemic.

Challenges with respect to changing type of work environment and establishing uninterrupted data streams during the pandemic are important to quantify the impact of the pandemic on maritime activity and global trade in general. Our showcase of the importance of AI and machine learning as it pertains to stringency index demonstrates spatiotemporal heterogeneity in factors that impact maritime traffic and supply lines. The stringency as a proxy for maritime activity shows that vessel activity between countries may not go back to normal immediately after the pandemic due to different levels of stringency measures throughout the world. Thus, concerted efforts taken by international organizations are required to restore the maritime traffic and intercontinental supply lines. As prolonged supply line disruptions are expected to cause major alterations to supply routes and trade deals, COVID-19 serves the latest pandemic of the digital age, where live maritime data and remote work can keep organizations and country levels afloat during time of crisis. A better understanding of the logistical chain and identification of weak points along the way as well as prioritization of essential goods will be key. This extends to terrestrial transportation, warehousing and distribution centers. The crew change system has to be reviewed and adapted to the circumstances based on how the pandemic is being addressed and controlled around the world, and the recognition of ship's crew as essential workers is also very important in maintaining operations. 


\section{References}

[1] Mayada Omer, Ali Mostashari, Roshanak Nilchiani, and Mo Mansouri. A framework for assessing resiliency of maritime transportation systems. Maritime Policy \& Management, 39(7):685-703, 2012.

[2] Michio Hongo, Yutaka Nagasaki, and Tomotaka Shoji. Epidemiology of esophageal cancer: Orient to occident. effects of chronology, geography and ethnicity. Journal of Gastroenterology and Hepatology, 24(5):729-735, 2009 .

[3] K David Patterson and Gerald F Pyle. The geography and mortality of the 1918 influenza pandemic. Bulletin of the History of Medicine, 65(1):4-21, 1991.

[4] Jonathan D Mayer. Geography, ecology and emerging infectious diseases. Social Science $\mathcal{G}$ Medicine, 50 $(7-8): 937-952,2000$.

[5] Diansheng Guo. Visual analytics of spatial interaction patterns for pandemic decision support. International Journal of Geographical Information Science, 21(8):859-877, 2007.

[6] Maged N Kamel Boulos and Estella M Geraghty. Geographical tracking and mapping of coronavirus disease covid-19/severe acute respiratory syndrome coronavirus 2 (sars-cov-2) epidemic and associated events around the world: how 21st century gis technologies are supporting the global fight against outbreaks and epidemics, 2020 .

[7] Geovanna Villacreses, Gabriel Gaona, Javier Martinez-Gomez, and Diego Juan Jijon. Wind farms suitability location using geographical information system (gis), based on multi-criteria decision making (mcdm) methods: The case of continental ecuador. Renewable Energy, 109:275-286, 2017.

[8] Timothy P Robinson. Spatial statistics and geographical information systems in epidemiology and public health. Advances in Parasitology, 47:81-128, 2000.

[9] Donna J Peuquet. Time in gis and geographical databases. Geographical Information Systems, 1:91-103, 1999 .

[10] Padam Bahadur Poudel, Mukti Ram Poudel, Aasish Gautam, Samiksha Phuyal, Chiran Krishna Tiwari, Nisha Bashyal, and Shila Bashyal. Covid-19 and its global impact on food and agriculture.

[11] Christophe Claramunt, Thomas Devogele, Sebastien Fournier, Valerie Noyon, Mathieu Petit, and Cyril Ray. Maritime gis: from monitoring to simulation systems. In Information Fusion and Geographic Information Systems, pages 34-44. Springer, 2007.

[12] Daniel Depellegrin, Mauro Bastianini, Amedeo Fadini, and Stefano Menegon. The effects of covid-19 induced lockdown measures on maritime settings of a coastal region. Science of The Total Environment, page 140123, 2020 .

[13] Chang Woon Nam et al. World economic outlook for 2020 and 2021. In CESifo Forum, volume 21, pages 58-59. Cesifo Institute-Leibniz Institute for Economic Research at the University of Munich, 2020.

[14] World Trade Organization (WTO). Trade set to plunge as COVID-19 pandemic upends global economy. Press release, 2020. URL https://www.wto.org/english/news_e/pres20_e/pr855_e.htm.

[15] World Trade Organization (WTO). Press Release. Information and Media Relations Division of the World Trade Organization, 2020.

[16] Hong Wang, Jianyong Shi, and Junqing Mei. Research on the development of the world's cruise industry during 2017-2018: Strong demands stimulate the sustainable high growth. In Report on the Development of Cruise Industry in China (2018), pages 3-35. Springer, 2019.

[17] Hirohito Ito, Shinya Hanaoka, and Tomoya Kawasaki. The cruise industry and the covid-19 outbreak. Transportation Research Interdisciplinary Perspectives, page 100136, 2020.

[18] Ziaul Haque Munim, Mariia Dushenko, Veronica Jaramillo Jimenez, Mohammad Hassan Shakil, and Marius Imset. Big data and artificial intelligence in the maritime industry: a bibliometric review and future research directions. Maritime Policy \& Management, pages 1-21, 2020.

[19] Bradley J Rhodes, Neil A Bomberger, and Majid Zandipour. Probabilistic associative learning of vessel motion patterns at multiple spatial scales for maritime situation awareness. In 2007 10th International Conference on Information Fusion, pages 1-8. IEEE, 2007.

[20] Ines Obradović, Mario Miličević, and Krunoslav Žubrinić. Machine learning approaches to maritime anomaly detection. Naše more: znanstveni časopis za more i pomorstvo, 61(5-6):96-101, 2014.

[21] Gökçe Çiçek Ceyhun. Recent developments of artificial intelligence in business logistics: A maritime industry case. In Digital Business Strategies in Blockchain Ecosystems, pages 343-353. Springer, 2020. 
[22] Dmitry Ivanov. Predicting the impacts of epidemic outbreaks on global supply chains: A simulation-based analysis on the coronavirus outbreak (covid-19/sars-cov-2) case. Transportation Research Part E: Logistics and Transportation Review, 136:101922, 2020.

[23] Branko Ristic, Barbara La Scala, Mark Morelande, and Neil Gordon. Statistical analysis of motion patterns in ais data: Anomaly detection and motion prediction. In 2008 11th International Conference on Information Fusion, pages 1-7. IEEE, 2008.

[24] James D Lyden, Robert R Hammond, David R Lyzenga, and RA Shuchman. Synthetic aperture radar imaging of surface ship wakes. Journal of Geophysical Research: Oceans, 93(C10):12293-12303, 1988.

[25] Virginia Fernandez Arguedas, Giuliana Pallotta, and Michele Vespe. Automatic generation of geographical networks for maritime traffic surveillance. In 17 th international conference on information fusion (FUSION), pages 1-8. IEEE, 2014.

[26] Arthur Getis and J Keith Ord. The analysis of spatial association by use of distance statistics. In Perspectives on spatial data analysis, pages 127-145. Springer, 2010.

[27] Liye Zhang, Qiang Meng, and Tien Fang Fwa. Big ais data based spatial-temporal analyses of ship traffic in singapore port waters. Transportation Research Part E: Logistics and Transportation Review, 129:287-304, 2019 .

[28] Robert Ward, Lee Alexander, Barrie Greenslade, and Anthony Pharaoh. IHO S-100: The New Hydrographic Geospatial Standard for Marine Data and Information. Canadian Hydrographic Conference, British Columbia, Canada, 2008.

[29] Adam Weintrit. Development of the imo e-navigation concept-common maritime data structure. In International Conference on Transport Systems Telematics, pages 151-163. Springer, 2011.

[30] International Maritime Organization (IMO). Draft e-Navigation strategy implementation plan. Report, 2014. URL http://www.imo.org/en/OurWork/Safety/Navigation/Pages/eNavigation.aspx.

[31] Thomas Hale, Samuel Webster, Anna Petherick, Toby Phillips, and Beatriz Kira. Oxford covid-19 government response tracker. Blavatnik School of Government, 25, 2020. 